\title{
Deliberate alteration of the visual evoked potential
}

\author{
CT TAN,${ }^{*}$ NMF MURRAY,${ }^{*}$ DIANE SAWYERS,${ }^{*}$ TJK LEONARD $\dagger$ \\ From the Departments of Clinical Neurophysiology, ${ }^{*}$ and Neuro-ophthalmology, $\dagger$ The National Hospital for \\ Nervous Diseases, Queen Square, London, UK
}

SUMMARY Seven out of 12 normal subjects could deliberately produce abnormal pattern-reversal visual evoked potentials (VEPs) which simulated disorders of the anterior visual pathways without detection. In six the mechanism was near-point accommodation and in one eccentric fixation. If voluntary suppression of the VEPs is suspected various modifications to the recording technique may be of value. These include the use of a large check size and stimulus field and binocular stimulation.

The pattern-reversal visual evoked potential (VEP) is an important and sensitive technique for detecting disease in the visual pathways. The most useful index of abnormality is prolongation of the latency of the major positivity, P100, either absolute or relative to the opposite eye. Amplitude reduction is less reliable but an inter-ocular amplitude asymmetry of $50 \%$ is generally regarded as abnormal. The major clinical application of the VEP is in the diagnosis of multiple sclerosis ${ }^{2}$ but it is of considerable value in the investigation of visual failure. Whereas demyelinating optic nerve lesions typically cause $\mathrm{P} \overline{\mathbf{1 0 0}}$ latency prolongation, compression of the anterior visual pathway is associated with waveform distortion and amplitude reduction, often with relatively minor latency increase. ${ }^{3}$ Stimulation of individual half-fields is helpful for localisation of chiasmal and post-chiasmal lesions ${ }^{4}$ and there are characteristic half-field waveform changes in optic nerve disorders which produce central or centrocaecal scotomata. ${ }^{5}$ Technical factors which influence the latency and amplitude of the VEP have been extensively studied and include the mean luminance, ${ }^{67}$ contrast, ${ }^{8}$ contour sharpness ${ }^{9}$ and pattern size. ${ }^{10}$

The VEP may be useful in distinguishing between functional and organic visual loss. " The amplitude of the $P \overline{100}$ is particularly affected by reduced visual acuity and the combination of grossly reduced acuity

\footnotetext{
Address for reprint requests: Dr NMF Murray, The National Hospital for Nervous Diseases, Queen Square, London WC1N 3BG, UK.

Received 10 October 1983.

Accepted 2 December 1983
}

Dr CT Tan's present address is Dept of Medicine, Faculty of Medicine, University of Malaya, Kuala Lumpur, Malaysia. and a well formed VEP of normal amplitude is a strong pointer to hysterical visual loss whereas an abnormal VEP may be taken as evidence for organic cause. A recent study by Bumgartner and Epstein ${ }^{12}$ has demonstrated that normal subjects can deliberately alter or obliterate their VEPs; this has obvious implications for the use for the technique as an objective test in the assessment of visual failure. In this study the need for co-operation of the subject is reaffirmed and methods of voluntary alteration of the VEP are investigated.

\section{Methods}

Six male and six female healthy subjects participated in the study. Ages ranged from 21 to 40 years and all had normal corrected visual acuity. The stimulus was a black and white checkerboard pattern slide projected via a rotating mirror on to a translucent screen. The pattern field subtended an angle of $18^{\circ}$ when placed 1 metre from the subject's eye. Slides with three different check sizes were used: $34^{\prime}$ ( in routine use in the laboratory), $22^{\prime}$ and $68^{\prime}$. The luminance of individual white squares was $1085 \mathrm{cdm}^{-2}$ and black squares $86 \mathrm{cdm}^{-2}$. Five channels of EEG were amplified and computer-averaged using a transverse occipital chain of $\mathrm{Ag} / \mathrm{Ag} \mathrm{Cl}$ recording electrodes placed so that the midline electrode was $5 \mathrm{~cm}$ above the inion with others $5 \mathrm{~cm}$ and $10 \mathrm{~cm}$ lateral to this. All were referred to a midfrontal electrode and the vertex was used for a ground. Pattern reversal occurred at $2 \mathrm{~Hz}$ and the EEG was sampled and averaged for $256 \mathrm{~ms}$ after the onset of each reversal. The time constant was 0.3 seconds $(-3 \mathrm{db})$ and the high frequency filter was at $300 \mathrm{~Hz}$. A display oscilloscope allowed assessment of artefact and EMG activity. At least two runs of 128 reversals were averaged for each eye separately; the subject fixated on a red spot at the screen centre and the other eye was patched. Abnormality was defined as P100 latency more than 2.5 standard deviations (SD) above the mean, interocular latency difference of at least $9 \mathrm{~ms}$ or $P \overrightarrow{100}$ amplitude less than $50 \%$ of the opposite eye. 
VEPs were recorded first with a 34' check stimulus while fixating normally (perceiving). The subject was then asked to "make the pattern disappear without closing the eye or moving the eye about" and the VEP was again recorded (non-perceiving). More precise instructions on ways of non-perceiving the stimulus was not given. The procedure was repeated using $22^{\prime}$ checks and $68^{\prime}$ checks, perceiving and non-perceiving. Ocular deviation and ptosis were carefully looked for and the subject immediately asked to correct. At the end of the test the subject was asked to describe the method used to make the pattern disappear. The eye patch was removed, the room fully illuminated and the subject demonstrated the manoeuvre while the positions of both eyes were noted.

In some subjects who were able to alter the VEP further experiments were performed during non-perceiving using a flash stimulus and using a 34' check pattern stimulus with binocular stimulation, half-field stimulation, the addition of lenses and prisms of various strengths and reduction of the eye to screen distance to $60 \mathrm{~cm}$.

\section{Results}

Mean values for $\mathrm{P} \overrightarrow{\mathbf{1 0 0}}$ latency and amplitude with the 12 subjects perceiving and non-perceiving the stimulus are given in table 1. All subjects had entirely normal VEPs according to a separate previously established control series when fixating and perceiving normally. Despite careful observation more than half of the subjects could voluntarily produce an abnormal VEP in one or both eyes when the standard $34^{\prime}$ check was used (table 2). Amplitude reduction was accomplished more easily than delay in the VEP; two subjects could abolish the P $\overline{100}$ and in seven there was a $50 \%$ fall in amplitude whereas four produced an absolute or relative abnormal latency prolongation (fig 1) without any detectable change in fixation. Seven subjects could increase the latency by $5 \mathrm{~ms}$, some by as much as $20 \mathrm{~ms}$, produc-

Table 1 Latency and amplitude of $P \overline{100}$ with subjects perceiving and non-perceiving the stimulus. 12 subjects, 24 eyes

\begin{tabular}{lllll}
\hline Check size & & $22^{\prime}$ & $34^{\prime}$ & $68^{\prime}$ \\
\hline Latency (ms) & & & & \\
Perceiving & Mean & 106 & $102 \cdot 8$ & $103 \cdot 3$ \\
& Range & $99-112$ & $95-107$ & $96-110$ \\
Non-perceiving & SD & $3 \cdot 5$ & $4 \cdot 0$ & $4 \cdot 4$ \\
& Mean & 115 & 109 & $108 \cdot 8$ \\
& Range & $99-131$ & $98-123$ & $97-126$ \\
Amplitude $(\mu \mathrm{V})$ & Absent & 3 & 3 & - \\
Perceiving & Mean & $10 \cdot 5$ & $10 \cdot 8$ & $9 \cdot 5$ \\
& Range & $4-28$ & $5-26$ & $4-19$ \\
Non-perceiving & Mean & $6 \cdot 3$ & $6 \cdot 5$ & $7 \cdot 9$ \\
& Range & $0-29$ & $0-26$ & $1-22$ \\
\hline
\end{tabular}

Table 2 Voluntary alteration of the VEP in 12 subjects

\begin{tabular}{|c|c|c|c|}
\hline Check size & $22^{\prime}$ & $34^{\prime}$ & $68^{\prime}$ \\
\hline \multicolumn{4}{|l|}{ Absent P100 } \\
\hline Eyes & 3 & 3 & - \\
\hline Subjects & 2 & 2 & - \\
\hline \multicolumn{4}{|l|}{$\begin{array}{l}\text { Abnormal P100 latency } \\
(>\text { Mean }+2.5 \text { SD) }\end{array}$} \\
\hline Eyes & 10 & 5 & 6 \\
\hline Subjects. & 6 & 3 & 3 \\
\hline \multicolumn{4}{|l|}{$\begin{array}{l}\text { Abnormal inter-eye latency } \\
\text { difference }(\geqslant 9 \mathrm{~ms})\end{array}$} \\
\hline \\
\hline Eyes & 11 & 10 & 5 \\
\hline \multirow{2}{*}{\multicolumn{4}{|c|}{ Total abnormal }} \\
\hline & & & \\
\hline Eyes & 13 & 12 & 7 \\
\hline Subjects & 7 & 7 & 4 \\
\hline
\end{tabular}

ing VEPs which might easily be regarded as evidence for optic nerve demyelination (fig 2). Small distorted VEPs typical of optic nerve compression were seen in others (fig 3).

Ability to alter the VEP was clearly affected by the size of the individual checks in the pattern stimulus (fig 4). More subjects could increase P100 latency with a small $\left(22^{\prime}\right)$ check stimulus whereas the number of abnormal VEPs was reduced when $68^{\prime}$ checks were used (table 2). Flash VEPs were virtually unchanged by deliberate non-perceiving of the stimulus.

Pupil size was monitored during all recordings; diameters ranged from $2-5 \mathrm{~mm}$ and never altered by more than $2 \mathrm{~mm}$. Four subjects reported that they "made the pattern go away" by near point focusing, ie focusing on an imagined point in front of the screen. There was no detectable eye movement but slight pupillary constriction was noted. However, when the other eye was uncovered it was seen to be sharply adducted. All four had VEPs of abnormal latency with $22^{\prime}$ checks, 3 with $34^{\prime}$ checks and one with $68^{\prime}$ checks. Two other subjects with abnormal VEPs could not describe the manoeuvre used but observation with both eyes uncovered indicated near point focusing. One subject produced a delayed small VEP by eccentric fixation on the top of the screen; this was not detected by the observers. One other produced a slight but not abnormal delay by fixating beyond the screen. The remaining four could not describe how they attempted to make the pattern disappear; no pupillary constriction or opposite eye adduction was seen and in these the VEP did not change.

VEPs with stimulation of individual right and left monocular half-fields were recorded in three subjects who could alter the whole-field VEP by near point focusing. The abnormal (ipsilateral) $P \overrightarrow{100}$ was 


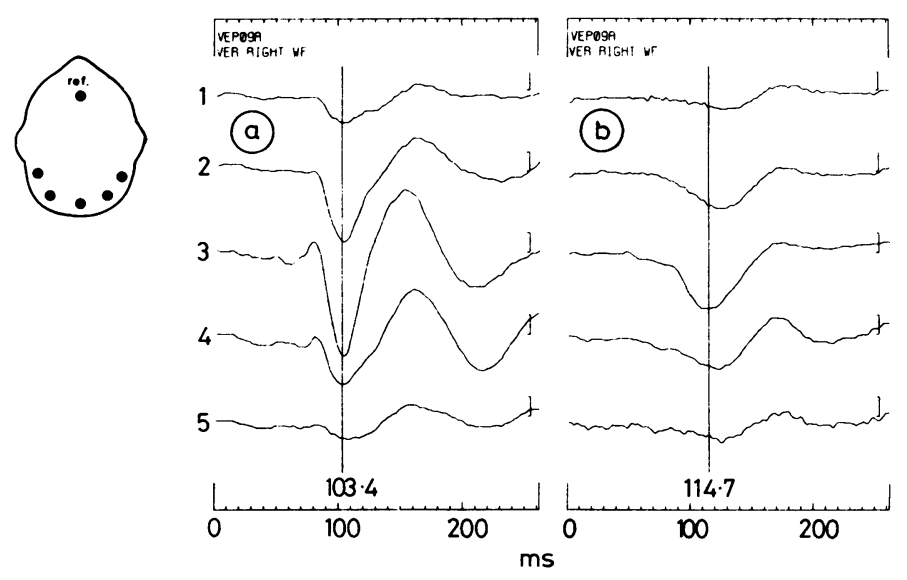

Fig 1 Right eye wholefield VEP: A, perceiving normally, $B$, deliberately non-perceiving the stimulus by near point focusing. Check size 34', calibration mark $2 \mu V$.
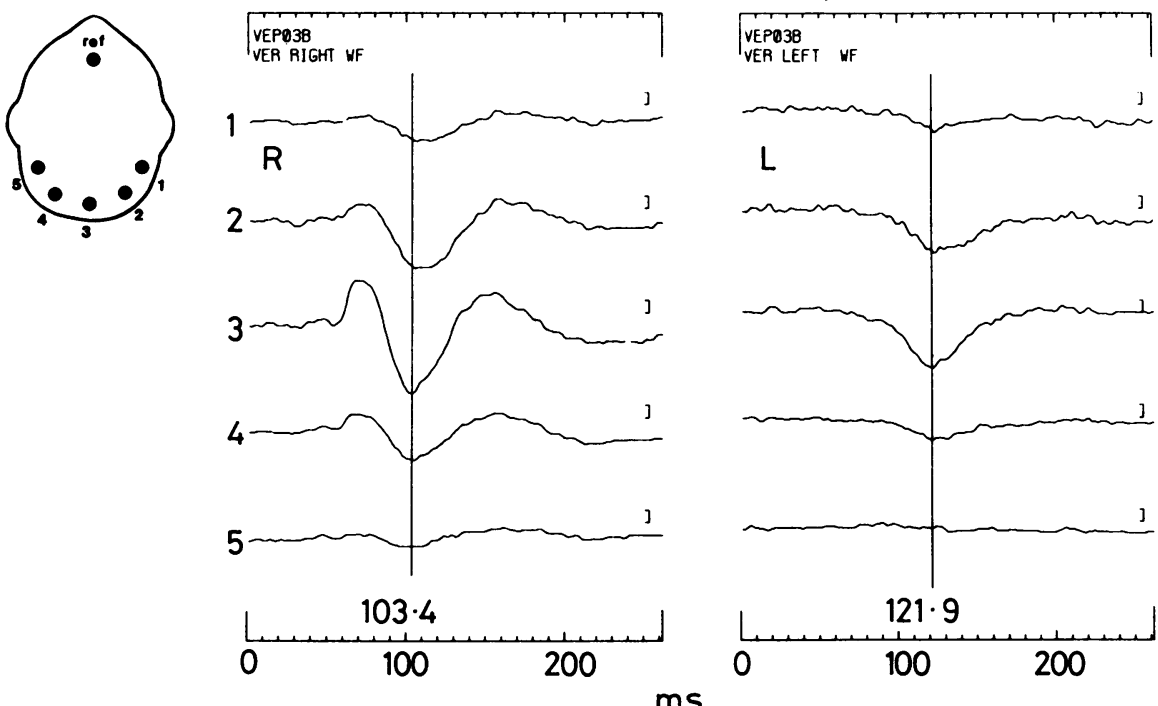

ms

Fig 2 Wholefield VEPs: the subject is fixating normally with the right eye, non-perceiving with the left eye. Marked delay of $P 100$ on the left, compatible with optic nerve demyelination. Check size 34', calibration mark $2 \mu V$.

seen in all the half-fields studied and none of the subjects showed a prominent contralateral P $\overline{135}$ to account for the delayed major positivity on full field stimulation. Binocular VEPs were recorded in two of these subjects; they were unable to produce abnormal VEPs without detection of adduction by observers.

In two subjects VEPs were recorded during near point focusing while lenses of various dioptres were inserted. Both showed some improvement: in the abnormal VEP with the addition of -3 dioptre lenses and dramatic improvement with -6 dioptre lenses (fig 5) but positive lenses did not normalise the VEP. The insertion of base-out prisms of up to +8 dioptres and base-in prisms of up to +24 dioptres had little effect on the abnormal P100.

Reduction in the distance between eye and screen made alteration of the VEP by near point focusing more difficult. Table 3 summarises the VEP data in three subjects with the screen at 1 metre and $60 \mathrm{~cm}$ from the eye, the angle subtended at the eye by each check being maintained at $34^{\prime}$. 

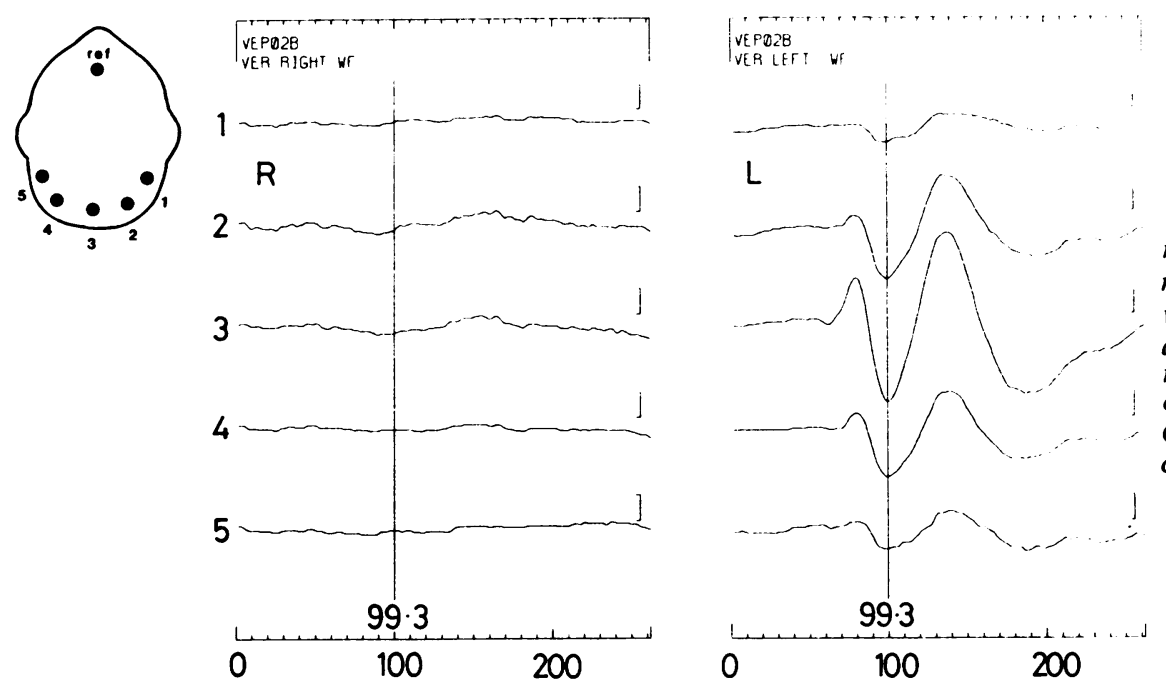

Fig 3 Wholefield VEPs:

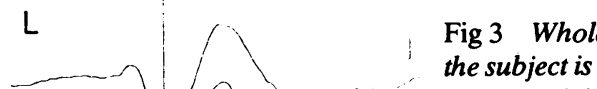

the subject is

non-perceiving with the right eye, fixating normally with the left eye. Grossly attenuated $P 100$ on the right, compatible with optic nerve compression. Check size 34', calibration mark $2 \mu V$.
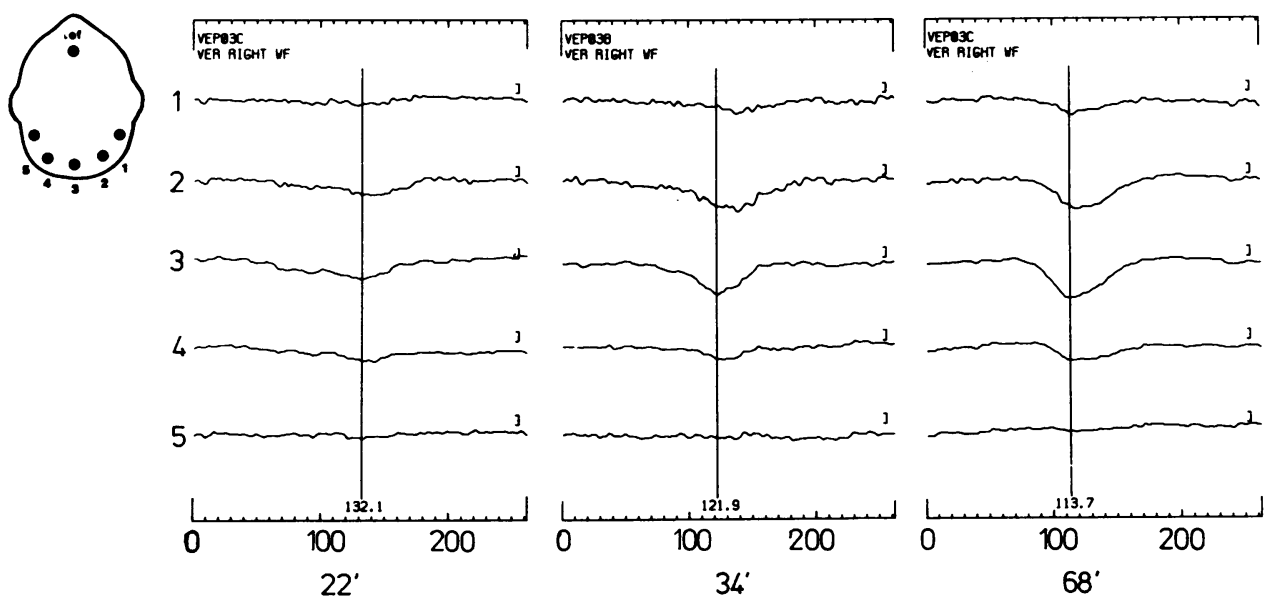

Fig 4 Right eye wholefield VEPs during near accommodation using pattern stimuli of 3 check sizes. $V$ oluntary suppression of the VEP is increased by reduction in the check size. Calibration mark $2 \mu V$.

\section{Discussion}

This study confirms the observation ${ }^{12}$ that normal subjects can deliberately alter the VEP to produce responses typical of disorders of the anterior visual pathway such as demyelination and compression without being easily detected.

Near point focusing was found to be the most successful method of altering the VEP. Near point focusing has three associated reflexes: pupillary constriction, convergence and near accommodation. ${ }^{13}$ This study suggests that the last of these three is particularly implicated in voluntary VEP alteration.
Reduction of pupil diameter from $8 \mathrm{~mm}$ to $2 \mathrm{~mm}$ reduces retinal illumination by more than $1 \log$ unit, a change known to prolong $\mathrm{P} \mathbf{1 0 0}$ latency by more than $10 \mathrm{~ms}^{67}$ However, in our subjects pupillary change did not exceed $2 \mathrm{~mm}$ and this alone was inadequate to account for the latency prolongation observed. Although there was marked adduction of the covered eye, movement of the tested eye was minimal, insufficient to shift the retinal image away from the macular area. This was confirmed by halffield studies which demonstated a true delay of the macular-derived $\mathrm{P} \overline{\mathbf{1 0 0}}$ component rather than enhancement of the paramacular P135. Further- 

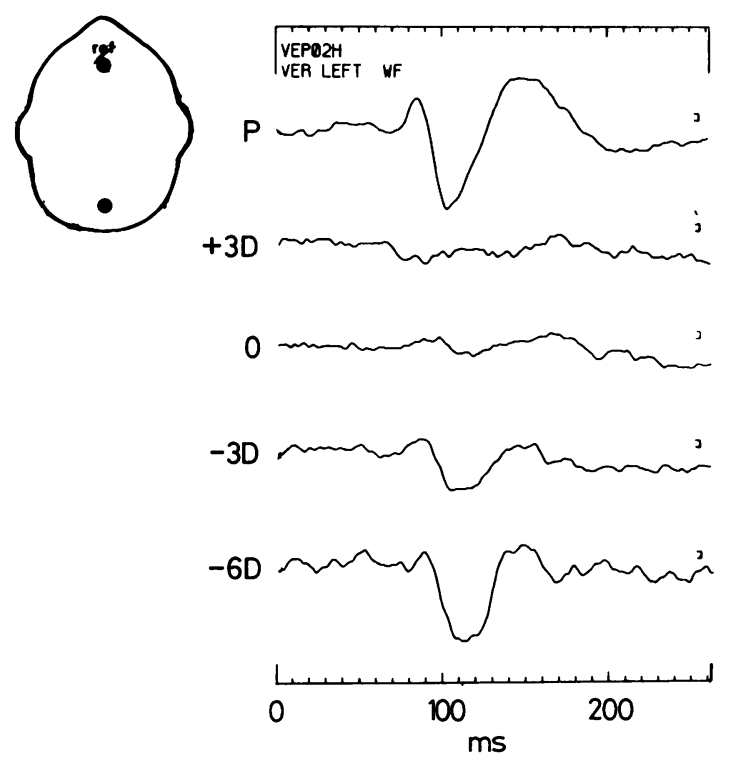

Fig 5 Left eye wholefield VEPs, mid-occipital recording electrode only shown here. From above: normal perceiving $(P) V E P$ and $V E P s$ during non-perceiving by near accommodation with the insertion of lenses of various dioptres $(+3 D$, none, $-3 D$ and $-6 D)$. The insertion of a -6 dioptre lens results in almost complete restoration of the response. Check size 22', calibration mark $2 \mu \mathrm{V}$.

more the use of a base-out prism to shift the retinal image medially did not reverse the altered VEP during near point focusing, further evidence against convergence per se being the cause of the VEP change.

$\mathrm{P} \overline{10} \overline{0}$ latency can be prolonged and amplitude reduced by the use of defocusing lenses and this is particularly the case when stimulus check size is small. ${ }^{14} 15$ We found that voluntary suppression of the VEP was enhanced by the use of a small check and was made more difficult by decreasing the distance between eye and screen. In addition the abnormal VEP produced by near point focusing

Table 3 VEPs during perceiving and non-perceiving by near point accommodation with the stimulus at $100 \mathrm{~cm}$ and $60 \mathrm{~cm}$ from the eye. Mean of data from 3 subjects, 6 eyes. Check size 34' at both distances

\begin{tabular}{llc}
\hline & Latency $(\mathrm{ms})$ & Amplitude $(\mu \mathrm{V})$ \\
\hline $100 \mathrm{~cm}$ from screen & & \\
Perceiving & 104.6 & 13.4 \\
Non-perceiving & 121.7 & 4.3 \\
$60 \mathrm{~cm}$ from screen & 106.6 & 12.0 \\
Perceiving & 115.9 & 7.3 \\
\hline
\end{tabular}

could be corrected by the addition of negative lenses. These facts suggest that near accommodation producing blurring of the pattern image on the retina is the principle mechanism involved.

Awareness of the possibility of deliberate alteration of the VEP is crucial for detecting a malingerer or hysteric. If the suspicion is raised that abnormal VEPs are factitious several modifications of the VEP technique may help to confirm this. Observation of the pupil may reveal miosis but this was not dramatic in our subjects and is by no means easy in a darkened recording room, especially in a subject with brown irises or wearing spectacles. Careful checking for ocular convergence is essential but it may be confined to the covered eye. Recording the VEP with binocular stimulation may be helpful; convergence may now be obvious or alternatively VEPs to binocular stimulation may be of considerably shorter latency and larger amplitude than when each eye is tested separately. Increasing the stimulus check size makes voluntary alteration more difficult but improvement in the VEP with increased check size does not per se confirm the suspicion of hysteria; we have noted that the delay in the $\mathrm{P} \overline{\mathbf{1 0 0}}$ is more pronounced with small checks in some patients with subclinical optic neuritis. Sensitivity must be weighed with specificity; a robust stimulus such as flash or large check pattern is less susceptible to voluntary alteration or the effects of uncorrected refractive error but is also less sensitive in detecting optic nerve disease.

One subject used far accommodation to produce a small delay in the VEP. In laboratories where the stimulus screen is relatively close to the eye, for example $50 \mathrm{~cm}$ this method of voluntary alteration may be more important. Another subject altered the VEP by fixating on the upper edge of the screen, as has previously been reported by Uren et al. ${ }^{16}$ This suggests that though the use of a small stimulus field may improve the detection rate in optic neuritis ${ }^{17} 18$ it also makes ocular non-compliance by eccentric fixation more difficult to detect.

In conclusion normal subjects can deliberately produce abnormal VEPs by manoeuvres such as near point focusing and near accommodation which are not apparent to a careful observer. Techniques such as the use of large checks, a large stimulus field and binocular stimulation may be helpful in confirming this but it must be recognised that these techniques can reduce the accuracy of the VEP in detecting disease of the visual pathways.

\section{References}

' Halliday AM, McDonald WI, Mushin J. Visual evoked responses in the diagnosis of multiple sclerosis. $\mathrm{Br}$ Med J 1973;4:661-4. 
${ }^{2}$ Asselman P, Chadwick DW, Marsden CD. Visual evoked responses in the diagnosis and management of patients suspected of multiple sclerosis. Brain 1975;98:261-82.

${ }^{3}$ Halliday AM, Halliday E, Kriss A, McDonald WI, Mushin J. The pattern-evoked potential in compression of the anterior visual pathways. Brain 1976;99:357-74.

${ }^{4}$ Blumhardt LD, Barrett G, Halliday AM. The asymmetrical visual evoked potential to pattern reversal in one half field and its significance for the analysis of visual field defects. Br J Ophthalmol 1977;61:454-61.

${ }^{5}$ Kriss A, Carroll WM, Blumhardt LD, Halliday AM. Pattern-and flash-evoked potential changes in toxic (nutritional) optic neuropathy. In: Courjon J, Maugiere F, Revol M, eds. Clinical applications of Evoked Potentials in Neurology. New York: Raven Press, 1982;11-19.

${ }^{6}$ Halliday AM, McDonald WI, Mushin J. Delayed pattern evoked responses in optic neuritis in relation to visual acuity. Trans Ophthalmol Soc UK 1973;93:315-25.

${ }^{7}$ Cant BR, Hume AL, Shaw NA. Effects of luminance on the pattern visual evoked potential in multiple sclerosis. Electroencephalogr Clin Neurophysiol 1978;45:496-504.

${ }^{8}$ Spekreijse H, Van der Tweel LA, Suidema T. Contrast evoked potentials in man. Vision Res 1973;13:1577601.

${ }^{9}$ Kulikowski J. Separation of occipital potentials related to the detection of pattern and movement. In: Desmedt JE, ed. Visual Evoked Potentials in Man: New Developments. Oxford: Clarendon Press, 1977;184-96.
${ }^{10}$ Harter RM, White CT. Effects of contour sharpness and check size on visually evoked cortical potentials. Vision Res 1968;8:701-11.

${ }^{11}$ Halliday AM. Evoked responses in organic and functional sensory loss. In: Fessard A, Lelord G, eds. Activités Évoquées et leur Conditionnment chez l'Homme Normal et en Pathologie Mentale. Paris: Editions Iserm, 1973;189-212.

12 Bumgartner J, Epstein CM. Voluntary alteration of visual evoked potentials. Ann Neurol 1982;12:475-8.

${ }^{13}$ Duke-Elder S. System of Ophthalmology, London: Henry Kimpton. $1971 ; \mathrm{Vol} X I I$, Neuro-ophthalmology: 695.

${ }^{14}$ Van Lith GH, Van Marle GW, Bartl G, VijfwinkelBruminga S. Visual acuity and checkerboard potentials with defocusing lenses. In: Lawwill T, ed. Docum Ophthalmol. The Hague: Junk, 1976;13:13-19.

${ }^{15}$ Sokol S, Moskowitz A. Effects of retinal blur on the peak-latency of the pattern evoked potential. Vision Res 1981;21:1279-86.

${ }^{16}$ Uren SM, Stewart P, Crosby PA. Subject co-operation and the visual evoked response. Invest Ophthalmol Vis Sci 1979; 18:648-52.

${ }^{17}$ Hennerici M, Wenzel D, Freund HJ. The comparison of small size rectangle and checkerboard stimulation for the evaluation of delayed visual evoked responses in patients suspected of multiple sclerosis. Brain 1977; 100:119-36.

${ }^{18}$ Nilsson B. Visual evoked responses in multiple sclerosis: comparison of two methods for pattern reversal. $J$ Neurol Neurosurg Psychiatry 1978;41:499-504. 